\title{
Transgenic mice and their impact on kidney research
}

\author{
Isabelle Rubera • Edith Hummler • Friedrich Beermann
}

Received: 21 November 2008 / Accepted: 25 November 2008 / Published online: 16 December 2008

(C) Springer-Verlag 2008

\begin{abstract}
The kidney is a key organ in the maintenance of ion and fluid homeostasis and specific transport systems localized along the nephron guarantee this function. Due to its large functional heterogeneity, experiments on the whole organ level cannot be easily performed, and thus more refined tools are needed, like for example the development of specific recombination systems to gain knowledge on the physiological role of single proteins implicated in ion transport. This review introduces the transgenic technology developed over the past decades, and then focuses on recent strategies for generating kidney-specific gene targeting, over-expression, and gene ablation in mice, that will help to understand the physiological role of proteins implicated in salt and water balance in the kidney.
\end{abstract}

\section{Rubera}

CNRS-FRE 3093, Université de Nice Sophia-Antipolis, 06108 Nice Cedex 2, France

E. Hummler $(\bowtie)$

Département de Pharmacologie et de Toxicologie, University of Lausanne,

Rue du Bugnon 27,

CH-1005 Lausanne, Switzerland

e-mail: Edith.Hummler@unil.ch

\section{E. Hummler}

Transgenic Animal Facility (TAF),

University of Lausanne and University Hospitals,

Rue du Bugnon 27,

1005 Lausanne, Switzerland

\section{F. Beermann}

ISREC (Swiss Institute for Experimental Cancer Research),

School of Life Sciences,

Ecole Polytechnique Fédérale de Lausanne (EPFL),

Ch. des Boveresses 155,

1066 Epalinges, Switzerland
Keywords Transgenic $\cdot$ Knockout $\cdot$ Mouse $\cdot$ Kidney Gene targeting $\cdot$ Cre recombinase $\cdot$ Epithelial Na channels . Epithelial cell $\cdot$ Medulla $\cdot$ Membrane transport

\section{Transgenic techniques}

Transgenic technology—an introduction

The genome alters during evolution or by specific breeding, a process that can be accelerated by inducing genetic modifications. This involves transgenic technology which allows to modify the genome (here, principally, of the mouse) at will and enables us to address specific scientific questions. Alternatively, germ cells of mice can be treated with mutagenic agents, as X-rays or ENU. The phenotype of the resulting mouse is scanned for specific defects, as exemplified by the recent efforts of the mouse clinic (GSF, Munich)[62]. Random alterations cannot compete for these directed modifications of the genome, such as classical transgenesis or knockout-related techniques. In the case of a transgene introduced by pronuclear injection, lentivirus or ES cell-mediated gene transfer, the insertion will be random, and is not linked to the endogenous locus if it exists. In contrast, knockout-related transgenesis will achieve a specific genetic modification at a given gene locus (Fig. 1, Table 1).

The history of transgenic mouse technology has existed for already several decades (Fig. 2). First transgenic experiments have been published 30 years ago, following infection of mouse embryos with viruses or retroviruses $[41,43]$. Next, the generation of mice by microinjecting DNA into one of the pronuclei of a fertilized mouse oocyte $[24,110]$ still represents the most commonly used technique of generating transgenic mouse lines up to now and 
Fig. 1 Transgenic mice can be obtained by adding new genetic information or by removing or mutating a gene already present in the genome

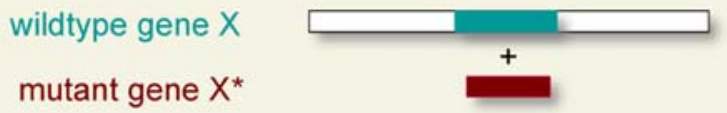

Gene addition

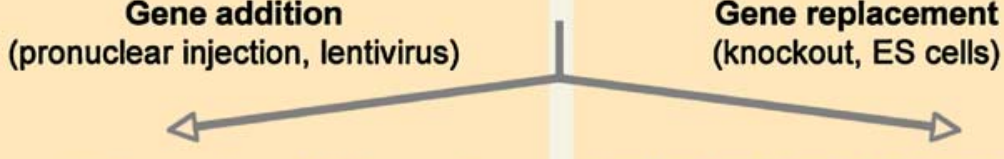

mutant gene inserted at new site

mutant gene replaces normal gene

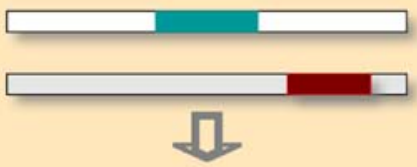

mutant and normal gene are present

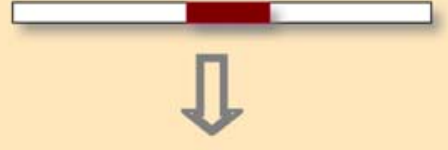

only mutant gene is present remained then nearly unchanged over the past three decades. Thousands of transgenic constructs have since been generated to answer a whole variety of scientific questions in biomedical research. Whereas earlier review articles could still follow the whole range of transgenic mice $[42,69,90]$, nowadays, reviews focus on specific topics, as for example disease models or organ-specific transgenesis $[39,50]$. Later in the 1980s of the past century, mouse embryonic stem cells (ES cells) isolated from the inner cell mass of preimplantation embryos (blastocyst stage) were established $[18,58]$ and first successful genetic manipulations of ES cells and generation of mice carrying the modification was reported more than 20 years ago [25]. A combination of gene-targeting approaches and these ES cells then allowed to generate the first knockout mouse, published in 1989 [93, 105]. The generation of such genetically engineered mice was honored in 2007 when the Nobel Prize for Medicine was attributed to Oliver Smithies, Mario Capecchi, and Martin Evans [56].

In the 1990s, a major breakthrough came up with the elaboration of the Cre/loxP-mediated recombination system [88], allowing to modify the genome either in the adult organism, or only in a specific tissue [45, 64]. First mice carrying so-called conditional alleles were published in the early 90 s $[26,27]$, and, since then, the number of strains carrying conditional alleles or expressing Cre recombinase is steadily increasing. Only recently, another transgenic approach has emerged, using lentiviral vectors [55], that contributed to two major aspects, first allowing to manipulate species other than the mouse [94], and second, to silence gene expression in vivo using siRNA-expressing vectors [80]. Lentivirus-mediated transgenesis can be a very

Table 1 A comparison of transgenic mice (pronuclear injection) and mice generated by homologous recombination (ES cells, knockout)

\begin{tabular}{|c|c|c|}
\hline & Transgenic mice (pronuclear injection) & Transgenic mice (ES cells and knockout) \\
\hline Purpose & Gain-of-function & Loss-of-function, change-of-function \\
\hline \multirow[t]{3}{*}{ Studies } & Overexpression & Knockout \\
\hline & Define regulatory elements & A gene is absent or modified \\
\hline & Disease model & Disease model \\
\hline \multirow[t]{3}{*}{ Technique } & Injection of DNA into fertilized oocytes & Electroporation of DNA into ES cells \\
\hline & & Injection of ES cells into blastocysts \\
\hline & Transfer to oviduct of pseudopregnant female & Transfer to oviduct/uterus of pseudopregnant female \\
\hline First mouse & Transgenic founder mouse (F0) & Chimera \\
\hline \multirow[t]{3}{*}{ Integration } & Multiple copies & One copy \\
\hline & Head-to-tail (tandem) & One integration site (independent integration sites, if several copies) \\
\hline & Random & Random or directed \\
\hline \multirow[t]{2}{*}{ Construct } & Minigene & Targeting construct \\
\hline & Regulatory sequence-cDNA-polyA & $5^{\prime}$ homology-replacement- $3^{\prime}$ homology \\
\hline
\end{tabular}

Main differences between transgenic mice obtained by pronuclear injection (transgenic mice in the common sense) and homologous recombination in embryonic stem cells (knockout) 


\begin{tabular}{l|l|}
\hline 1974 & Viral infection of embryo during cleavage \\
1980 & Pronuclear injection of DNA constructs \\
1981 & Establishment of mouse embryonic stem cells \\
1986 & Germline transmission of genetically modified ES cells \\
1987 & First gene targeting in ES cells \\
1989 & First knockout mice \\
1994 & Conditional mutants using the Cre/loxP system in mice \\
2002 & Lentiviral transgenesis
\end{tabular}

Fig. 2 A timeline of transgenic technology, referring to several classical publications $[10,24,26,43,55,105,110]$

efficient way of generating transgenic mice. Due to the multiple independent integrations of the lentivirus, the establishment of stable lines can be tedious, but, nevertheless, the lentiviral approach represents a valid alternative when the effect of a transgene or mutant protein can be analyzed at the stage of the founder mice.

Adding genetic information to the genome: pronuclear injection

In the following, we will detail the various aspects of gene "addition" in mice. Here, for ease of simplicity, we will focus on pronuclear injection which is the technique by far the most often applied today. ES-cell-mediated transgenesis will not be covered here, and specificities of lentiviral techniques are mainly related to the design of lentiviral vectors. Hence, the interested reader is referred to some recent articles and reviews for a more profound discussion $[72,80,89,101]$.

The various steps of the pronuclear injection technique are outlined in Fig. 3. Usually, female mice are superovulated with gonadotrophic hormones to synchronize the females and to obtain a larger number of maturing follicles per female. This can be done with almost any mouse strain, even though the efficiency is rather variable [65] and high doses of gonadotrophins may affect maturation and meiotic division in a certain percentage of oocytes [6]. F1 hybrid mouse strains are most often used, as for example B6D2F1 mice with the mother, B6 (C57BL/6), and the father, D2 (DBA/2). Alternatively, inbred strains as $\mathrm{FVB} / \mathrm{n}$ or $\mathrm{C} 57 \mathrm{BL} /$ 6 might be used $[65,73,102]$. Fertilized oocytes (zygotes) are recovered when the paternal and maternal nucleus ("pronucleus") are not fused yet. DNA solution is injected into one of the pronuclei until visible swelling. For lentiviral transgenesis, the virus solution is injected below the glycoproteinic shell of the oocyte, the zona pellucida, which is less harmful for later survival. In both methods, surviving oocytes are then retransferred into the oviduct of pseudopregnant females. Such females have been obtained by mating with sterilized males (principally obtained by vasectomy), keeping them hormonally apt to accept a conception. If the procedure is successful, pregnancy of the mouse is visible after about 10-11 days, and mothers will give rise to birth after 19-20 days. Generally, the eventual transgenicity of the offspring is tested at weaning. The overall efficiency then depends, amongst other parameters, on the type of the construct, the quality of the DNA preparation, the choice of the mouse strain and the individual skill and performance of the experimenter.

The pronuclear injection technique allows the use of transgenic constructs of several $100 \mathrm{~kb}$ in size, using for example YACs (yeast artificial chromosomes), PACs (P1derived artificial chromosomes) or BACs (bacterial artificial chromosomes) [23, 63, 103]. However, most often classical transgenic minigene constructs are used, which are up to $10-15 \mathrm{~kb}$ in length and are composed of a regulatory sequence which specifies the tissue of expression, a coding
Fig. 3 Scheme of the procedure for generation of transgenic mice by pronuclear injection
Mating and recovery of fertilized oocytes

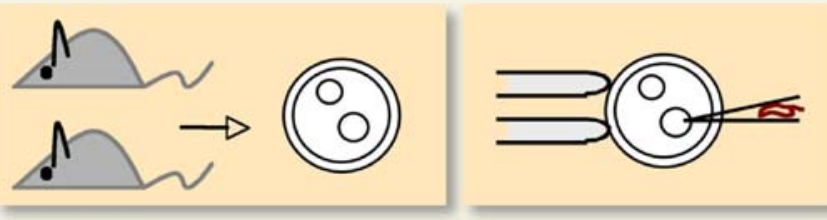

Birth of putative transgenics

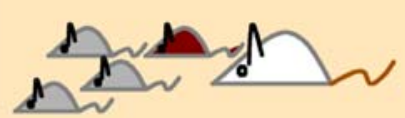

Pronuclear injection
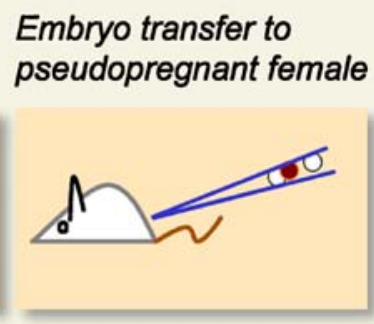

Analysis by PCR or Southern blot

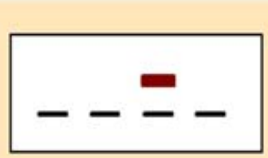


region (e.g., cDNA) and polyadenylation sequences. Often, intronic sequences are added to the design of the constructs, since this might enhance the stability of the transcript and increase the chance of expression [9]. Following removal of vector sequences, the concentration of the insert is calibrated to $1-5 \mathrm{ng} / \mu \mathrm{l}$, and $1-2 \mathrm{pl}$ of solution injected into one of the pronuclei.

Even though the injection of the DNA is effected during the one-cell stage (the fertilized oocyte), integration can occur later, for example in one cell of a four-cell stage. In consequence, the resulting transgenic mouse does not contain the transgene in all cells but only in a few of them-the mouse is mosaic for this transgene. As a consequence, the transgene may not be present in germ cells, and no transgenic offspring obtained. The integration of the transgene is random and multiple copies are normally integrated into a single site of the genome, but their chromosomal integration varies in independent transgenic mice. This integration normally occurs "head-to-tail" (tandem) in the same orientation, and encompasses mostly less than ten to 20 copies, even though higher copy numbers (up to 1,000) have been observed [54]. For example, when using a $S V 40: \because c-M y c$ transgene, more than 50 copies of the transgene were inserted on chromosome 8, whereas the endogenous $c-M y c$ gene on chromosome 15 remained untouched [5]. A transgene is stably integrated and then inherited in a Mendelian fashion, and not lost over many generations [2]. Due to the randomness of integration, an endogenous gene may be affected, thereby rendering it unfunctional or modified in its expression. For example, a transgenic mouse line expressing the key enzyme in pigmentation, tyrosinase, showed skeletal malformations and polydactyly. It turned out that the transgenic insertion affected the Gli3 gene, a member of the hedgehog signaling pathway, thereby generating a new allele at this locus [78].

\section{Embryonic stem cells and vectors}

In contrast to the pronuclear, but also lentiviral transgenesis, ES (embryonic stem) cell-mediated approaches require two steps, first the genetic manipulation performed in cell culture, and second, the injection of such modified cells into mouse blastocysts that are 3.5-day-old-mouse embryos. Just before implantation, they can be recovered by flushing uteri $[65,73]$. ES cells themselves are derived from the inner cell mass of mouse blastocysts, and need to be kept undifferentiated to maintain their stem cell characteristics. The leukemia inhibiting factor (Lif) known to be required to prevent differentiation of ES cells is either produced by irradiated primary mouse fibroblasts that are co-cultured with the ES cells and/or can also be added in its recombinant form to the culture medium. Several well- characterized ES cell lines are available which are most often derived from different substrains of $129[97,106]$ and are of male sex. Embryonic stem cells should exhibit unlimited self-renewal capacity but still maintain pluripotency. They can be amplified and manipulated similar to standard cell cultures in vitro, and it is feasible to selectfollowing electroporation of gene constructs into for example $10^{7}$ cells - rare genetic modifications. Concordantly, when ES cells carrying a dominant allele of Agouti as $\mathrm{A}^{\mathrm{W}}$ (white-bellied agouti, from a substrain of 129) are injected into mouse blastocysts of the strain C57BL/6 (a, nonagouti), mice can result, which contain both C57BL/6and 129-derived cells and are identified by coat color chimerism. ES cells then not only colonize somatic tissues of the blastocyst donor (C57BL/6), as evident from the coat color, but also the germ line. Following breeding of chimeras, the new modification can be fixed and bred as a new transgenic strain $[65,73]$.

Over the past two decades, various kinds of genetic modifications have been introduced in ES cells, ranging from random insertions (enhancer or gene trap approaches, [114]) and classical transgenic constructs $[8,25]$ to specific targeting of a sequence of interest (homologous recombination). In the mid 1980s, Mario Capecchi and coworkers showed that a gene defect in somatic cells can be rescued by introducing the correct sequence, which then recombines with flanking homologous sequences [104]. Consequently, this technique of homologous recombination allowed to generate mice in which a gene is deleted or specifically mutated [93, 105]. The classical knockout vectors used for constitutive gene inactivation contained a neomycin resistance gene to replace an endogenous exon - at the best to remove the ATG or any other vital region of the gene together with $5^{\prime}$ and $3^{\prime}$ homologous sequences of about $5 \mathrm{~kb}$ in total. Following electroporation into ES cells, selection markers and molecular analyses by PCR and Southern blot are required to identify the rare event of homologous recombination. Once identified, the ES cell clone is amplified, characterized and used for blastocyst injection to establish the mouse line [73]. As final outcome, a mouse line is generated where function of a specific gene is abolished or altered by replacement with a neomycin resistance gene. Using recombinase recognition sites in the targeting construct (loxP or frt, see below) the neomycin gene can be removed by further breeding to recombinaseexpressing mice, to exclude any unwanted side effects. Nowadays, the technique of homologous recombination not only allows to generate null-mutations (classical knockout), but also subtle mutations (any kind of point mutations, microdeletions). Mouse models with chromosomal rearrangements (macrodeletions, inversions or translocations) as found in the human genome can be generated [11, 98]. Moreover, knock-in approaches allow not only to remove, 
but to replace the gene by for example another member of the same gene family, to address issues of redundancy [57].

\section{Conditional knockouts}

Since constitutive deficiency of a gene/protein may lead to embryonic or early perinatal lethality, conditional knockouts have been developed to study a mutation in a given cell type or in a timely controlled manner. The development of site-specific recombinases and recognition sites from bacteriophages (Cre/loxP-mediated recombination) or yeast (Flp/frt-mediated recombination) was a prerequisite for this technique (as depicted in Fig. 4). Two recombinase recognition sequences (34 bp loxP sites) are positioned in the same direction flanking a DNA sequence of interest (generally containing one or several exons). The Cre recombinase recognizes these loxP sites, induces a recombination which leads to excision of all DNA sequences between the two loxP sites, leaving one loxP site at this locus. The newer generation of knockout vectors possesses loxP sites $5^{\prime}$ and $3^{\prime}$ of a vital region, for example around the ATG-containing exon. In addition, the neomycin cassette is flanked by frt recognition sequences for Flp recombinase to eliminate the selection marker that may interfere with the expression of the modified gene. Following ES cell manipulations as detailed elsewhere [73] (see also above), a mouse is obtained which carries an exon flanked by two loxP sites and a neomycin cassette flanked by two frt sites. By mating this mouse with a transgenic strain expressing Flp recombinase in germ cells ("germ line deleter" [81]) the neomycin resistance gene is removed.

The Cre recombinase can be expressed in the germ cells or ubiquitously, thereby generating a constitutive knockout mouse, or in a cell type-specific and/or inducible manner
[64]. Tissue-specificity is achieved by a tissue-specific promoter that targets Cre expression to the cell type or organ of interest. Consequently, the gene knockout is restricted to this cell type/organ. In its inducible version, Cre recombinase expression can be dependent on a doxycycline-controlled system [92], or alternatively, activity, and translocation of Cre recombinase to the nucleus is dependent on tamoxifen treatment [60]. This is due to a fusion of the Cre recombinase to the binding domain of the estrogen receptor (CreERT), and, upon administration of the synthetic hormone tamoxifen, Cre recombinase will enter the nucleus and exert Cre/loxP-mediated recombination. Functioning of the Cre/loxP-mediated recombination system can be tested by the use of reporter mouse strains that provide a mean to monitor specificity of Cre recombinase activity in vivo, e.g., using the Rosa26R strain [99]. Here, a STOP cassette flanked by two loxP sites and preceding a lac Z reporter gene was introduced at the ROSA26 locus. Cre activity results in removal of the STOP and permits lacZ expression which might be specific to the target tissue of interest thereby validating the tissuespecificity of the Cre transgenic line [30].

\section{Transgenes targeted to the kidney}

\section{Kidney-specific transgenic expression}

Genetic engineering in mice nowadays allows us to express transgenes specifically in the kidney, even though anatomic complexity of the kidney makes it difficult to select appropriate promoters that target a specific cell type, e.g., along the nephron. Even, a conditional approach is required (Fig. 4) when the constitutive knockout affects embryonic

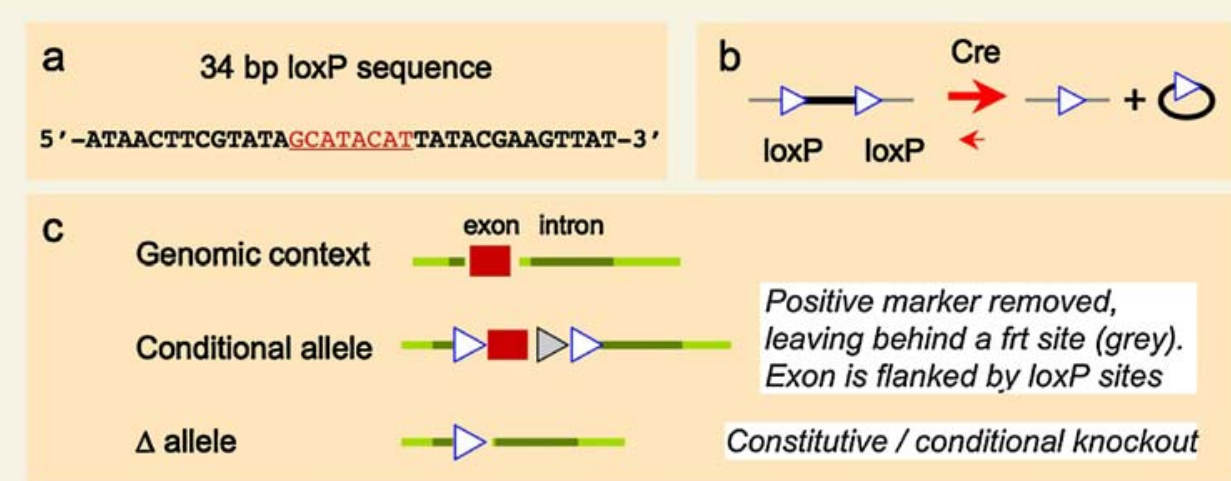

Fig. 4 Cre/loxP technology to generate and use conditional alleles. a The specificity of the Cre/loxP system is given by the 34 bp loxP recognition sequence consisting of two 13-bp palindromic sequences and an 8-bp core sequence. b Upon presence of Cre recombinase the loxP-flanked sequence is removed leaving one loxP sequence in the genome. c Scheme of the different alleles, wildtype, floxed (conditional) and deleted. In particular, conditional mutants are characterized as carrying floxed alleles (flox flanked by loxP sites). This allows elimination of the gene function of interest by transgenic expression of Cre recombinase 
development or leads to complex phenotypes. The ability to perform kidney-specific recombination is dependent on the choice of kidney-specific promoters used to drive the expression of Cre recombinase in vivo (Table 2). Such regulatory promoter sequences have to be tested to find out whether they are able to drive the expression of a reporter gene in a nephron-segment-specific manner. Classically, a promoter region of interest is linked to a reporter gene (lacZ, GFP, luciferase) and transgenic mice are generated and analyzed for expression in embryos and various organs. Since Cre expression in such lines in organs beside the kidney has not always been studied extensively, ectopic Cre activity may influence the phenotype of the animal.

We had recently generated transgenic mice that do express Cre recombinase exclusively in the renal proximal tubule [86] using the high-capacity (type2) $\mathrm{Na}^{+}$/glucose cotransporter promoter. Other promoters, like, e.g., the HoxB7 promoter have been used for targeting Cre recombinase expression to the cortical duct of the kidney but expression has also been reported selectively in the spinal cord and the dorsal root ganglia [113]. Hox genes encode homeodomain-containing proteins that control, e.g., mammalian kidney morphogenesis. During embryonic develop- ment, some Hoxd genes regulate the metanephric mesenchyme-ureteric bud interactions, and maintenance of structural integrity of tubular epithelia is differentially controlled consistent with their specific expression profile [14]. Mice expressing Cre from the renin promoter are not only useful for kidney-specific recombination, but affect a whole variety of cells given that renin-expressing cells are precursors for certain epithelial and extrarenal cells [95]. And, finally, promoters like, e.g., nephrin affect efficiently the glomeruli as shown for the glomerulus-specific knockout of VEGF-A that led to congenital and acquired renal diseases [17]. The expression of most available Cre recombinase lines is constitutive, but more recently, models have been developed using inducible and ligand-regulated promoter systems to spatially and temporally control Cre recombinase expression in specific renal cell types. Different mouse lines exist which use the $\mathrm{CreER}^{\mathrm{T} 2}$ system, where the Cre recombinase is fused to a mutant human estrogen receptor (ER) and gets only active upon tamoxifen administration [16, 49, 71]. Similarly, a transgenic strain expressing androgen-inducible Cre recombinase has been reported. Here, the transgene is expressed specifically in the renal proximal tubule in male mice, but not expressed in

Table 2 A survey of Cre transgenic mouse strains targeting the kidney and specific nephron segments

\begin{tabular}{|c|c|c|c|}
\hline Cre line & Promoter & Expression & Reference \\
\hline$\gamma \mathrm{GT}::$ Cre & Rat $\gamma$-glutamyl transpeptidase II & PT (cort. tubules) & {$[40]$} \\
\hline iL1-sglt2::Cre & Mouse sodium-glucose cotransporter 2 & PT & {$[86]$} \\
\hline PEPCK::Cre & Rat phosphoenolpyruvate carboxykinase & PT & {$[32,79]$} \\
\hline GGT::CreER ${ }^{\mathrm{T} 2}$ & Mouse $\gamma$-glutamyl transpeptidase II & $\mathrm{PT}(\mathrm{S} 3)$ & [16] \\
\hline KAP2::iCre & Mouse kidney androgen-regulated protein & $\mathrm{PT}$ & [53] \\
\hline Ksp1.3::Cre & Mouse kidney-specific cadherin & All, TAL, CD & [96] \\
\hline KspCad::CreER ${ }^{\mathrm{T} 2}$ & Mouse kidney-specific cadherin & All segments & {$[48,49]$} \\
\hline Ksp::CreER ${ }^{\mathrm{T} 2}$ & Mouse kidney-specific cadherin & All, CD & [71] \\
\hline THP::Cre & Mouse Tamm-Horsfall protein & TAL & [100] \\
\hline apoE::Cre & Human apolipoprotein (apo) E & PT, DT & {$[52]$} \\
\hline AQP2::Cre & Human aquaporin-2 & $\mathrm{CD}$ (principal cells) & {$[67]$} \\
\hline AQP2::Cre & Mouse aquaporin-2 & CD (principal cells) & [22] \\
\hline AQP2::Cre & Mouse aquaporin-2 & Late CNT, CD (principal cells) & [83] \\
\hline Hoxb7::Cre & Mouse $H o x b 7$ & $\mathrm{CD}$ & [113] \\
\hline Hoxb7::CreEGFP & Mouse $\operatorname{Hoxb7}$ & $\mathrm{CD}$ & {$[118]$} \\
\hline Neph::Cre & Mouse Nphs1 (nephrin) & Glomeruli, podocytes & {$[17]$} \\
\hline NPHS2::Cre & Human podocin (NPHS2) & Glomeruli & [61] \\
\hline Ren $1^{\mathrm{d}}:$ Cre & Mouse renin $1^{\mathrm{d}}$ & Juxtaglomerular cells, afferent arterioles & [95] \\
\hline Pax2::Cre & Mouse Pax2 & Glomeruli, renal tubules, $\mathrm{CD}$, nephric duct & [68] \\
\hline Pax 8::Cre & Mouse $\operatorname{Pax} 8$ & Glomeruli, renal tubules, nepric duct, mesonephros & [7] \\
\hline 11HSD2::iCre & Mouse 11ß-hydroxysteroid dehydrogenase 2 & Kidney (expression in other tissues!) & {$[66]$} \\
\hline Pax8::rtTA/LC-1::Cre & Mouse $\operatorname{Pax} 8$ & Renal tubule except glomeruli & {$[92,108]$} \\
\hline Osr2::(Ires)Cre & Mouse Odd-skipped related-2 & Glomeruli & {$[47]$} \\
\hline Hnf4a::(Ires)Cre & Mouse hepatocyte nuclear factor $\alpha$ & Cortex (tubules) & [109] \\
\hline
\end{tabular}

Some of the strains show Cre expression in other organs as for example gonads (GGT::CreER ${ }^{T 2}$, THP::Cre, AQP2::Cre), ureteral epithelium (Hoxb7::Cre) or liver and brain (THP::Cre, PEPCK::Cre). Please note that Cre recombinase activity in other organs has not always been extensively analyzed and/or documented

$P T$ Proximal tubule, TAL thick ascending limbs of Henle's loop, $C N T$ connecting tubule, $D T$ distal tubule, $C D$ collecting duct 
females unless induced by testosterone [53]. Another efficient and versatile tool for acute and chronic modulation of renal tubular function in transgenic mice has been recently described by Traykova-Brauch and coworkers [108]. They generated Pax8::rtTA mice which strongly express the transgene in a highly kidney-specific, uniform and tetracycline-dependent manner. Both inducible and reversible, renal diseases such as polycystic kidney disease, renal fibrosis and renal cancer can be modeled in transgenic mice upon doxycycline application.

A further application of targeting transgenes to the kidney might be the production of human therapeutic proteins: the uromodulin gene promoter has been used to produce recombinant proteins (growth hormone, $\alpha 1$-antitrypsin, erythropoietin) in the urine of transgenic mice [115, 116, 119].

\section{Mouse models for kidney diseases}

This part of the review exemplifies the use of transgenic mouse models for studying renal and electrolyte physiology by targeting gene expression specifically to epithelial cells of the renal tubule. This has been useful, e.g., for studying the intrarenal renin-angiotensin-aldosterone system (RAAS) that is implicated in the development of hypertension, and therefore an important mediator of systemic blood pressure and electrolyte balance. Data obtained from transgenic mice expressing the rat and human angiotensinogen gene [15, 87], the human renin gene [51], and the rat angiotensin II type 1 receptor-associated protein ARAP1 gene [29] to proximal tubules using the kidney-androgenregulated protein (KAP) promoter underlined the role of the proximal tubule-specific renin-angiotensin system in the regulation of blood pressure and renal function. Further, kidney-specific expression of a cDNA encoding a mutant form of a protein as identified in human is an attractive approach to determine its effects on kidney function. Igarashi et al. expressed a dominant-negative form of the mouse HNF-1 $\beta$ protein that corresponds to the A263insGG mutation as found in human under the control of the kidney-specific Ksp-cadherin promoter. The mice developed maturity-onset diabetes of the young-5 (MODY5), with renal cysts and renal failure, similar to the human condition. This kidney-specific transgenic experiment clearly demonstrated that mutations of HNF-1 $\beta$ are sufficient to produce kidney cysts and that the renal cystic disease is intrinsic to the kidney and not secondary to diabetes [31]. To investigate the pathogenic mechanism of the $P k d 1$ gain-of-function mutations in the renal tubular epithelium, Trudel and coworkers have produced a transgenic mouse strain that overexpressed the murine $P k d l$ gene using a modified $P k d l$ BAC. These transgenic mice displayed features similar to autosomal dominant polycystic kidney disease (ADPKD) demonstrating that $P k d 1$ gain-offunction mutations in the kidney are sufficient to reproduce a renal ADPKD phenotype as found in human [84, 103].

Chung and colleagues used a transgenic approach to address effects on urine concentration and kidney function in vivo in epithelial cells of the renal collecting tubules [46]. Overexpression of a dominant-negative form of the osmotic response element-binding protein (OREBP) under the control of the kidney-specific Ksp-cadherin promoter led to polyuria and polydipsia indicating that OREBP is an important regulator of the urine-concentrating mechanism [46]. The knockout of aldose reductase as one of the osmoresponsive genes transcriptionally regulated by TonEBP/OREBP has lost the ability to concentrate urine; in contrast, a knock-in of an aldose reductase transgene (under control of the Ksp-cadherin promoter) onto the aldose reductase knockout background revealed an incomplete rescue of the knockout phenotype. The authors concluded that aldose reductase, in addition to its role in osmoregulation, may be essential for the full maturation of the urine-concentrating mechanism [112].

Kidney-specific knockout models for renal salt and water homeostasis

In the following paragraph, we will give examples of renal tubule epithelial cell-specific knockouts of proteins implicated in salt and water homeostasis. Peroxisome proliferator-activated receptor subtype $\gamma$ (PPAR $\gamma$ ) is the pharmacological target of thiazolidinediones (TZDs) and, within the kidney, is predominantly expressed in the collecting duct. TZDs are widely used antidiabetic drugs, but have well-established side effects such as fluid retention leading to weight gain and occasionally to edema and heart failure [70]. To address the mechanism of TZDs-induced fluid retention, Breyer and colleagues used a mouse strain transgenic for Cre recombinase driven by $14 \mathrm{~kb}$ of the human AQP2 5'-flanking region (AQP2::Cre) [28, 67]. Yang et al. used $A Q P 2: \because$ Cre mice using $11 \mathrm{~kb}$ of the mouse $A Q P 2$ 5'-flanking region [117]. Using either Cre strain, removal of PPAR $\gamma$ in the collecting duct prevented body weight gain and fluid retention induced by TZDs. These data also underlined a PPAR $\gamma$-dependent pathway of sodium transport in the collecting duct, with TZDs-induced fluid retention. Concerning renal regulation of water balance and urinary concentrating process, mice lacking AQP2 expression in CD but with sustained AQP2 expression in CNT using HoxB $7::$ Cre mice were generated [82]. Mutant mice survived to adulthood but exhibited severe polyuria and deterioration of urinary concentrating ability after water deprivation. The model demonstrated that AQP2 expression in CNT is sufficient for postnatal survival and in $\mathrm{CD}$ is essential for the regulation of body water 
homeostasis. To better understand the role of the medullary endothelin-1 (ET-1) system in regulating renal salt and water excretion and systemic blood pressure, Kohan and colleagues have engineered several mouse models using Cre/loxP technology and AQP2::Cre transgenic mice expressing Cre recombinase in the collecting duct. Mice with CD-specific downregulation of ET-1 are hypertensive and have impaired sodium excretion in response to sodium loading [1]. These mice also have decreased ability to excrete an acute water load and enhanced sensitivity to vasopressin [19]. Moreover, in these animals, urinary prostaglandin E2 (PGE2) excretion was increased which partly compensates for loss of ET-1 [21]. In addition, the role of ET receptors was also assessed by disrupting $\mathrm{ET}_{\mathrm{A}}$ or $\mathrm{ET}_{\mathrm{B}}$ receptors specifically in $\mathrm{CD}$. $\mathrm{ET}_{\mathrm{B}}$ loss-of-function in $\mathrm{CD}$ results in hypertension and reduced $\mathrm{Na}^{+}$excretion after an acute $\mathrm{Na}^{+}$load leading to the conclusion that $\mathrm{ET}_{\mathrm{B}}$ receptors partially mediate ET-1 functions as a natriuretic and antihypertensive factor [20]. In a separate study, the authors highlighted the role of $\mathrm{CD} \mathrm{ET}_{\mathrm{A}}$ receptors in reducing ET-1 inhibition of vasopressin signaling [22]. Recently, the role for nitric oxide (NO) pathway in CDderived ET-1-induced natriuresis, diuresis, and hypotension was unveiled [91]. With regard to regulation of urine concentration mechanism, the role of the Pax transactivation-domain interacting protein (PTIP) in the inner renal medulla was studied by tissue-specific gene deletion using Ksp 1.3::Cre mice, demonstrating the functional importance of PTIP in urine-concentrating ability by modulating arginine vasopressin receptor 2 and AQP2 expression in the renal collecting ducts [44].

To assess the role of a proximal tubular endocytic receptor, megalin, in calcium and phosphate homeostasis, two reports analyzed kidney-specific megalin knockout mice generated by conditional gene targeting using apoE:: Cre mice. Renal specific deletion of megalin resulted in plasma vitamin D deficiency, hypocalcemia and bone disease [52]. Proximal tubular type IIa sodium phosphate cotransporter (NaPi-IIa) handling is also affected in this model and disruption of endocytosis resulted in reduced phosphaturia [3]. These two studies highlighted an essential role of the megalin receptor pathway in calcium and phosphate homeostasis. Tiwari et al. removed the insulin receptor specifically in renal epithelial cells in the mouse revealing its role in the kidney for sodium balance and blood pressure [107]. To examine the role of the mineralocorticoid receptor (MR) in sodium homeostasis, a new $A Q P 2::$ Cre mouse strain was used to inactivate $\mathrm{MR}$ in collecting duct and late connecting tubule [83]. The mutant mice exhibited normal renal sodium excretion associated with elevated aldosterone levels on a standard diet. However, this compensation by the late distal convoluted tubule and early connecting tubule fails when challenged with a low-salt diet leading to loss of body weight associated with increased renal sodium and water excretion.

Lastly, we will discuss the genetic dissection of the highly amiloride-sensitive epithelial sodium channel $\mathrm{ENaC}$ along the nephron as an example of a constitutively as well as conditionally targeted sodium transporting protein in the kidney. Over the past years, we have generated an allelic series of mutations at the ENaC (Scnnl) gene loci showing that any modified expression the $\mathrm{ENaC}$ subunits may cause a kidney disease $[4,36,39,74,76,111]$. Constitutive gene inactivation of all three subunits revealed that the absolute $\mathrm{ENaC}$ expression is essential for survival [4, 35, 59]. Removal of the $\alpha \mathrm{ENaC}$ subunit (Scnn1a) resulted in completely abolished $\mathrm{ENaC}$ activity, whereas inactivation of the $\mathrm{BENaC}$ (Scnnlb) and $\gamma \mathrm{ENaC}$ (Scnnlg) subunit led to reduced $\mathrm{ENaC}$ activity. Mice without $\mathrm{BENaC}($ Scnn $1 b)$ and $\gamma \mathrm{ENaC}$ (Scnnlg) develop hyperkalemia and die soon after birth [4]. Failure to thrive and lethargy are associated with urinary $\mathrm{Na}^{+}$wasting, $\mathrm{K}^{+}$retention, and increased plasma aldosterone concentrations (for review, see [39]). Mutations that result in hypofunction in the kidney are expected to induce a salt wasting syndrome similar to type 1 pseudohypoaldosteronism (see, for review [33]). Various mouse lines have been generated in which the $\mathrm{ENaC}$ activity ranges from hypoactive channels $(5-15 \%$ of total $\mathrm{ENaC}$ activity) to hyperactive channels $(>150 \%$ of total $\mathrm{ENaC}$ activity; for review, see [37]. Reduced ENaC activity in mice bearing $\mathrm{ENaC}$ mutations led to clinical symptoms similar to PHA-1 (pseudohypoaldosteronism type 1) ranging from mild (e.g., mutation in the $\mathrm{BENaC}$ gene locus [74]) to severe phenotype (e.g., $\gamma \mathrm{ENaC}$ knockout mice [4]). We further introduced one of the classical Liddle mutations (R566STOP) into the mouse BENaC (Scnn1b) gene locus, thereby generating mice, which reproduce to a large extent the clinical symptoms of Liddle patients [76]. These mice present an impaired $\mathrm{ENaC}$ internalization, and exhibit ENaC-mediated transport features that are consistent with an overall increased $\mathrm{ENaC}$ activity [75]. Interestingly, mineralocorticoid-mediated up-regulation of $\mathrm{ENaC}$ expression and function is still maintained in these mice which show a remarkable high sensitivity to aldosterone in vivo $[13,75]$. Renal cells from these mice exhibit hyperactive apical vasopressin-regulated CFTR $\mathrm{Cl}^{-}$conductance [12] that could contribute to the enhanced $\mathrm{NaCl}$ reabsorption observed in the distal nephron of patients with Liddle's syndrome (for review, see [34]). Finally, we used conditional gene targeting of $\mathrm{ENaC}$ to genetically dissect the aldosterone-induced $\mathrm{ENaC}$-mediated sodium reabsorption along the nephron. When a floxed allele for the $\alpha \mathrm{ENaC}$ subunit (Scnn1a lox/lox mice) [38] was crossed with the HoxB $7::$ Cre line this resulted in a complete abolishment of $\mathrm{ENaC}$ function in the cortical collecting duct (CCD), but not in the early segments of the aldosterone-sensitive distal 
nephron (ASDN), the late distal convoluted tubule (DCT) and connecting tubule (CNT)[85]. Surprisingly, we found that $\mathrm{ENaC}$ expression in the $\mathrm{CCD}$ is not a prerequisite for normal sodium and potassium balance. We further concluded that aldosterone-regulated $\mathrm{ENaC}$ activity might occur more proximal in the early ASDN. Further tools to dissect $\mathrm{ENaC}$ function along the nephron include the $A Q P 2:: C r e$ mice that have been recently used to knockout the mineralocorticoid MR receptor in the CNT and CCD (Christensen et al., manuscript in preparation; [83]) and the Pax8::rtTA/LC1::Cre double transgenic line [108], that should eliminate $\mathrm{ENaC}$ function in all kidney cells with exception of glomeruli when bred to the floxed $\alpha \mathrm{ENaC}$ mice $\left(S \operatorname{snn} 1 a^{\text {flox }}\right)$. Elimination of $\mathrm{ENaC}$ in the whole kidney will certainly indicate to which extent the kidney contributes to the whole net sodium homeostasis of the body. The ultimate proof of the aldosterone-dependent sodium reabsorption will be the specific inactivation of $\mathrm{ENaC}$ within the DCT2 and CNT by crossing the floxed $\mathrm{ENaC}$ mice, e.g., with mice that express the Cre recombinase under the control of the TRPV5 promoter [77]. The identification of the exact nephron segment involved in aldosterone-dependent sodium reabsorption will help to develop a more refined treatment for hypertension.

\section{Conclusion}

In summary, renal cell-specific expression and renal cellspecific knockout approaches are effective tools for demonstrating in vivo importance of genes in ion and water homeostasis in the adult kidney. With a growing list of nephron-segment-specific promoters and nephronsegment-specific Cre mouse lines, any gene of interest can now be expressed or removed within the nephron to study renal physiology and pathophysiology. Such studies will finally lead to more refined drugs in kidney disease.

Acknowledgments Work in the laboratory of FB is supported by grants from The Swiss National Science Foundation and The Swiss Cancer League. Work in the laboratory of EH is supported by a grant from the Swiss National Science Foundation.

\section{References}

1. Ahn D, Ge Y, Stricklett PK, Gill P, Taylor D, Hughes AK, Yanagisawa M, Miller L, Nelson RD, Kohan DE (2004) Collecting duct-specific knockout of endothelin-1 causes hypertension and sodium retention. J Clin Invest 114:504-511

2. Aigner B, Fleischmann M, Muller M, Brem G (1999) Stable long-term germ-line transmission of transgene integration sites in mice. Transgenic Res 8:1-8

3. Bachmann S, Schlichting U, Geist B, Mutig K, Petsch T, Bacic D, Wagner CA, Kaissling B, Biber J, Murer H, Willnow TE
(2004) Kidney-specific inactivation of the megalin gene impairs trafficking of renal inorganic sodium phosphate cotransporter (NaPi-IIa). J Am Soc Nephrol 15:892-900

4. Barker PM, Ngugen MS, Gatzy JT, Grubb B, Norman H, Hummler E, Rossier B, Boucher RC, Koller B (1998) Role of gammaENaC subunit in lung liquid clearance and electrolyte balance in newborn mice: insights into perinatal adaptation and pseudohypoaldosteronism. J Clin Invest 102:1634-1640

5. Beermann F, Hummler E, Franke U, Hansmann I (1988) Allocation of a transgenic c-myc integration site to mouse chromosome 8B3-C1. Cytogenet Cell Genet 49:311-312

6. Beermann F, Jenderny J, Hummler E, Hansmann I (1987) Inheritance of a meiosis I error expressed in mouse oocytes and modulated by a maternal factor. Genet Res 49:239-243

7. Bouchard M, Souabni A, Busslinger M (2004) Tissue-specific expression of cre recombinase from the Pax 8 locus. Genesis 38:105-109

8. Bradley A, Liu P (1996) Target practice in transgenics. Nat Genet 14:121-123

9. Brinster R, Allen J, Behringer R, Gelinas R, Palmiter R (1988) Introns increase transcriptional efficiency in transgenic mice. Proc Natl Acad Sci U S A 85:836-840

10. Brinster R, Chen H, Trumbauer M, Senear A, Warren R, Palmiter R (1981) Somatic expression of herpes thymidine kinase in mice following injection of a fusion gene into eggs. Cell 27:223-231

11. Buchholz F, Refaeli Y, Trumpp A, Bishop JM (2000) Inducible chromosomal translocation of AML1 and ETO genes through Cre/loxP-mediated recombination in the mouse. EMBO Rep 1:133-139

12. Chang CT, Bens M, Hummler E, Boulkroun S, Schild L, Teulon J, Rossier BC, Vandewalle A (2005) Vasopressin-stimulated CFTR Cl-currents are increased in the renal collecting duct cells of a mouse model of Liddle's syndrome. J Physiol 562:271-284

13. Dahlmann A, Pradervand S, Hummler E, Rossier BC, Frindt G, Palmer LG (2003) Mineralocorticoid regulation of epithelial $\mathrm{Na}+$ channels is maintained in a mouse model of Liddle's syndrome. Am J Physiol Renal Physiol 285:F310-F318

14. Di-Poi N, Zakany J, Duboule D (2007) Distinct roles and regulation for Hoxd genes in metanephric kidney development. PLoS Genet 3:2500-2514

15. Ding Y, Davisson RL, Hardy DO, Zhu LJ, Merrill DC, Catterall JF, Sigmund CD (1997) The kidney androgen-regulated protein promoter confers renal proximal tubule cell-specific and highly androgen-responsive expression on the human angiotensinogen gene in transgenic mice. J Biol Chem 272:28142-28148

16. Dworniczak B, Skryabin B, Tchinda J, Heuck S, Seesing FJ, Metzger D, Chambon P, Horst J, Pennekamp P (2007) Inducible Cre/loxP recombination in the mouse proximal tubule. Nephron Exp Nephrol 106:e11-e20

17. Eremina V, Wong M, Cui S, Schwartz L, Quaggin S (2002) Glomerular-specific gene excision in vivo. J Am Soc Nephrol 13:788-793

18. Evans M, Kaufman M (1981) Establishment in culture of pluripotent cells from mouse embryos. Nature 292:154-156

19. Ge Y, Ahn D, Stricklett PK, Hughes AK, Yanagisawa M, Verbalis JG, Kohan DE (2005) Collecting duct-specific knockout of endothelin-1 alters vasopressin regulation of urine osmolality. Am J Physiol Renal Physiol 288:F912-F920

20. Ge Y, Bagnall A, Stricklett PK, Strait K, Webb DJ, Kotelevtsev Y, Kohan DE (2006) Collecting duct-specific knockout of the endothelin B receptor causes hypertension and sodium retention. Am J Physiol Renal Physiol 291:F1274-F1280

21. Ge Y, Strait KA, Stricklett PK, Yang T, Kohan DE (2007) Role of prostaglandins in collecting duct-derived endothelin-1 regulation of blood pressure and water excretion. Am J Physiol Renal Physiol 293:F1805-F1810 
22. Ge Y, Stricklett PK, Hughes AK, Yanagisawa M, Kohan DE (2005) Collecting duct-specific knockout of the endothelin A receptor alters renal vasopressin responsiveness, but not sodium excretion or blood pressure. Am J Physiol Renal Physiol 289: F692-F698

23. Giraldo P, Montoliu L (2001) Size matters: use of YACs, BACs and PACs in transgenic animals. Transgenic Res 10:83-103

24. Gordon J, Scangos G, Plotkin D, Barbosa J, Ruddle F (1980) Genetic transformation of mouse embryos by microinjection of purified DNA. Proc Natl Acad Sci U S A 77:7380-7384

25. Gossler A, Doetschman T, Korn R, Serfling E, Kemler R (1986) Transgenesis by means of blastocyst-derived embryonic stem cell lines. Proc Natl Acad Sci U S A 83:9065-9069

26. Gu H, Marth JD, Orban PC, Mossmann H, Rajewsky K (1994) Deletion of a DNA polymerase $\beta$ gene segment in T cells using cell type-specific gene targeting. Science 265:103-106

27. Gu H, Zou Y, Rajewsky K (1993) Independent control of immunoglobulin switch recombination at individual switch regions evidenced through Cre-loxP mediated gene targeting. Cell 73:1155-1164

28. Guan Y, Hao C, Cha DR, Rao R, Lu W, Kohan DE, Magnuson MA, Redha R, Zhang Y, Breyer MD (2005) Thiazolidinediones expand body fluid volume through PPARgamma stimulation of ENaC-mediated renal salt absorption. Nat Med 11:861-866

29. Guo DF, Chenier I, Lavoie JL, Chan JS, Hamet P, Tremblay J, Chen XM, Wang DH, Inagami T (2006) Development of hypertension and kidney hypertrophy in transgenic mice overexpressing ARAP1 gene in the kidney. Hypertension 48:453459

30. Guyonneau L, Rossier A, Richard C, Hummler E, Beermann F (2002) Expression of Cre recombinase in pigment cells. Pigment Cell Res 15:305-309

31. Hiesberger T, Bai Y, Shao X, McNally BT, Sinclair AM, Tian X, Somlo S, Igarashi P (2004) Mutation of hepatocyte nuclear factor-1beta inhibits Pkhd1 gene expression and produces renal cysts in mice. J Clin Invest 113:814-825

32. Higgins D, Kimura K, Bernhardt W, Shrimanker N, Akai Y, Hohenstein B, Saito Y, Johnson R, Kretzler M, COhen C, Eckardt K, Iwano M, Haase V (2007) Hypoxia promotes fibrogenesis in vivo via HIF-1 stimulation of epithelial-tomesenchymal transition. J Clin Invest 117:3810-3820

33. Hummler E (1999) Implication of ENaC in salt-sensitive hypertension. J Steroid Biochem Mol Biol 69:385-390

34. Hummler E (2003) Epithelial sodium channel, salt intake, and hypertension. Curr Hypertens Rep 5:11-18

35. Hummler E, Barker P, Gatzy J, Beermann F, Verdumo C, Schmidt A, Boucher R, Rossier B (1996) Early death due to defective neonatal lung liquid clearance in aENaC-deficient mice. Nat Genet 12:325-328

36. Hummler E, Barker P, Talbot C, Wang Q, Verdumo C, Grubb B, Gatzy J, Burnier M, Horisberger J-D, Beermann F, Boucher R, Rossier BC (1997) A mouse model for the renal salt-wasting syndrome pseudohypoaldosteronism. Proc Natl Acad Sci USA 94:11710-11715

37. Hummler E, Beermann F (2000) Scnn1 sodium channel gene family in genetically engineered mice. J Am Soc Nephrol 11 (Suppl 16):S129-S134

38. Hummler E, Mérillat AM, Rubera I, Rossier BC, Beermann F (2002) Conditional gene targeting of the Scnn1a $(\mathrm{aENaC})$ gene locus. Genesis 32:169-172

39. Hummler E, Vallon V (2005) Lessons from mouse mutants of epithelial sodium channel and its regulatory proteins. J Am Soc Nephrol 16:3160-3166

40. Iwano M, Plieth D, Danoff TM, Xue C, Okada H, Neilson EG (2002) Evidence that fibroblasts derive from epithelium during tissue fibrosis. J Clin Invest 110:341-350
41. Jaenisch R (1976) Germ line integration and Mendelian transmission of the exogenous Moloney leukemia virus. Proc Natl Acad Sci U S A 73:1260-1264

42. Jaenisch R (1988) Transgenic animals. Science 240:1468-1474

43. Jaenisch R, Mintz B (1974) Simian virus 40 DNA sequences in DNA of healthy adult mice derived from preimplantation blastocysts injected with viral DNA. Proc Natl Acad Sci U S A 71:1250-1254

44. Kim D, Wang M, Cai Q, Brooks H, Dressler GR (2007) Pax transactivation-domain interacting protein is required for urine concentration and osmotolerance in collecting duct epithelia. $\mathrm{J}$ Am Soc Nephrol 18:1458-1465

45. Kwan K (2002) Conditional alleles in mice: practical considerations for tissue-specific knock-outs. Genesis 32:49-62

46. Lam AK, Ko BC, Tam S, Morris R, Yang JY, Chung SK, Chung SS (2004) Osmotic response element-binding protein (OREBP) is an essential regulator of the urine concentrating mechanism. $\mathrm{J}$ Biol Chem 279:48048-48054

47. Lan Y, Wang Q, Ovitt C, Jiang R (2007) A unique mouse strain expressing Cre recombinase for tissue-specific analysis of gene function in palate and kidney development. Genesis 45:618-624

48. Lantinga-van Leeuwen I, Leonhard W, van der Wal A, Breuning M, de Heer E, Peters D (2007) Kidney-specific inactivation of the Pkd1 gene induces rapid cyst formation in developing kidneys and a slow onset of disease in adult mice. Hum Mol Genet 16:3188-3196

49. Lantinga-van Leeuwen IS, Leonhard WN, van de Wal A, Breuning MH, Verbeek S, de Heer E, Peters DJ (2006) Transgenic mice expressing tamoxifen-inducible Cre for somatic gene modification in renal epithelial cells. Genesis 44:225-232

50. Larue L, Beermann F (2007) Cutaneous melanoma in genetically modified animals. Pigment Cell Res 20:485-497

51. Lavoie JL, Lake-Bruse KD, Sigmund CD (2004) Increased blood pressure in transgenic mice expressing both human renin and angiotensinogen in the renal proximal tubule. Am J Physiol Renal Physiol 286:F965-F971

52. Leheste JR, Melsen F, Wellner M, Jansen P, Schlichting U, Renner-Muller I, Andreassen TT, Wolf E, Bachmann S, Nykjaer A, Willnow TE (2003) Hypocalcemia and osteopathy in mice with kidney-specific megalin gene defect. FASEB J 17:247-249

53. Li H, Zhou X, Davis DR, Xu D, Sigmund CD (2008) An androgen-inducible proximal tubule-specific cre-recombinase transgenic model. Am J Physiol Renal Physiol 294:F1481F1486

54. Lo C (1986) Localization of low abundance DNA sequences in tissue sections by in situ hybridization. J Cell Sci 81:143-162

55. Lois C, Hong E, Pease S, Brown E, Baltimore D (2002) Germline transmission and tissue-specific expression of transgenes delivered by lentiviral vectors. Science 295:868-872

56. Mak T (2007) Gene targeting in embryonic stem cells scores a knockout in Stockholm. Cell 131:1027-1031

57. Malynn B, de Alboran I, O'Hagan R, Bronson R, Davidson L, DePinho R, Alt F (2000) N-myc can functionally replace c-myc in murine development, cellular growth, and differentiation. Genes Dev 14:1390-1399

58. Martin G (1981) Isolation of a pluripotent cell line from early mouse embryos cultured in medium conditioned by teratocarcinoma stem cells. Proc Natl Acad Sci U S A 78:7634-7638

59. McDonald FJ, Yang B, Hrstka RF, Drummond HA, Tarr DE, McCray PB, Stokes JB, Welsh MJ, Williamson RA (1999) Disruption of the beta subunit of the epithelial $\mathrm{Na}+$ channel in mice: hyperkalemia and neonatal death associated with a pseudohypoaldosteronism phenotype. Proc Natl Acad Sci U S A 96:1727-1731

60. Metzger D, Clifford J, Chiba H, Chambon P (1995) Conditional site-specific recombination in mammalian cells using a ligand- 
dependent chimeric Cre recombinase. Proc Natl Acad Sci U S A 92:6991-6995

61. Moeller M, Sanden S, Soofi A, Wiggins R, Holzman L (2003) Podocyte-specific expression of Cre recombinase in transgenic mice. Genesis 35:39-42

62. Mossbrugger I, Hoelzlwimmer G, Calzada-Wack J, QuintanillaMartinez L (2007) Standardized morphological phenotyping of mouse models of human diseases within the German Mouse Clinic. Verh Dtsch Ges Pathol 91:98-103

63. Murisier F, Aydin I, Guichard S, Brunschwiler S, Beermann F (2008) Expression from a bacterial artificial chromosome containing the Dct gene locus. Pigment Cell Mel Res 21:212215

64. Nagy A (2000) Cre recombinase: the universal reagent for genome tailoring. Genesis 26:99-109

65. Nagy A, Gertsenstein M, Vintersten K, Behringer R (2003) Manipulating the mouse embryo - a laboratory manual. Cold Spring Harbor Laboratory Press, Cold Spring Harbor, New York

66. Naray-Fejes-Toth A, Fejes-Toth G (2007) Novel mouse strain with Cre recombinase in 11 beta-hydroxysteroid dehydrogenase2-expressing cells. Am J Physiol Renal Physiol 292:F486-F494

67. Nelson RD, Stricklett P, Gustafson C, Stevens A, Ausiello D, Brown D, Kohan DE (1998) Expression of an AQP2 Cre recombinase transgene in kidney and male reproductive system of transgenic mice. Am J Physiol 275:C216-C226

68. Ohyama T, Groves A (2004) Generation of Pax2-Cre mice by modification of a Pax2 bacterial artificial chromosome. Genesis 38:195-199

69. Palmiter R, Brinster R (1986) Germ-line transformation of mice. Annu Rev Genet 20:465-499

70. Patel C, Wyne K, McGuire D (2005) Thiazolidenediones, peripheral oedema and congestive heart failure: what is the evidence? Diab Vasc Dis Res 2:61-66

71. Patel V, Li L, Cobo-Stark P, Shao X, Somlo S, Lin F, Igarashi P (2008) Acute kidney injury and aberrant planar cell polarity induce cyst formation in mice lacking renal cilia. Hum Mol Genet 17:1578-1590

72. Pfeifer A (2004) Lentiviral transgenesis. Transgenic Res 13:513522

73. Porret A, Mérillat A, Guichard S, Beermann F, Hummler E (2006) Tissue-specific transgenic and knockout mice. Meth Mol Biol 337:185-205

74. Pradervand S, Barker P, Wang Q, Ernst SA, Beermann F, Grubb B, Burnier M, Schmidt A, Bindels RJM, Gatzy J, Rossier BC, Hummler E (1999) Salt restriction induces pseudohypoaldosteronism type 1 in mice expressing low levels of the beta-subunit of the amiloride-sensitive epithelial sodium channel. Proc Natl Acad Sci U S A 96:1732-1737

75. Pradervand S, Vandewalle A, Bens M, Gautschi I, Loffing J, Hummler E, Schild L, Rossier BC (2003) Dysfunction of the epithelial sodium channel expressed in the kidney of a mouse model for Liddle syndrome. J Am Soc Nephrol 14:2219-2228

76. Pradervand S, Wang Q, Burnier M, Beermann F, Horisberger J-D, Hummler E, Rossier B (1999) A mouse model for Liddle's syndrome. J Am Soc Nephrol 10:2527-2533

77. Praetorius J, Fenton R, Füechtbauer E, Hofmeister M (2008) TRPV5-promoter driven expression of EGFP produces fluorescence in late DCT, CNT and early CCD. FASEB J 22:1159.16

78. Rachel R, Wellington S, Warburton D, Mason C, Beermann F (2002) A new allele of Gli3 and a new mutation, circletail (Crc), resulting from a single transgenic experiment. Genesis 33:55-61

79. Rankin EB, Tomaszewski JE, Haase VH (2006) Renal cyst development in mice with conditional inactivation of the von Hippel-Lindau tumor suppressor. Cancer Res 66:2576-2583

80. Raoul C, Abbas-Terki T, Bensadoun J, Guillot S, Haase G, Szule J, Henderson C, Aebischer P (2005) Lentiviral-mediated silencing of SOD1 through RNA interference retards disease onset and progression in a mouse model of ALS. Nature Med 11:423-428

81. Rodriguez C, Buchholz F, Galloway J, Sequerra R, Kasper J, Ayala R, Stewart A, Dymecki S (2000) High-efficiency deleter mice show that FLPe is an alternative to Cre-loxP. Nat Genet 25:139-140

82. Rojek A, Fuchtbauer EM, Kwon TH, Frokiaer J, Nielsen S (2006) Severe urinary concentrating defect in renal collecting duct-selective AQP2 conditional-knockout mice. Proc Natl Acad Sci U S A 103:6037-6042

83. Ronzaud C, Loffing J, Bleich M, Gretz N, Grone HJ, Schutz G, Berger S (2007) Impairment of sodium balance in mice deficient in renal principal cell mineralocorticoid receptor. J Am Soc Nephrol 18:1679-1687

84. Rossetti D, Chauveau D, Walker D, Saggar-Malik A, Winearls C, Torres V, Harris P (2002) A complete mutation screen of the ADPKD genes by DHPLC. Kidney Int 61:1588-1599

85. Rubera I, Loffing J, Palmer LG, Frindt G, Fowler-Jaeger N, Sauter D, Carroll T, McMahon A, Hummler E, Rossier BC (2003) Collecting duct-specific gene inactivation of alphaENaC in the mouse kidney does not impair sodium and potassium balance. J Clin Invest 112:554-565

86. Rubera I, Poujeol C, Bertin G, Hasseine L, Counillon L, Poujeol P, Tauc M (2004) Specific Cre/Lox recombination in the mouse proximal tubule. J Am Soc Nephrol 15:2050-2056

87. Sachetelli S, Liu Q, Zhang SL, Liu F, Hsieh TJ, Brezniceanu ML, Guo DF, Filep JG, Ingelfinger JR, Sigmund CD, Hamet P, Chan JS (2006) RAS blockade decreases blood pressure and proteinuria in transgenic mice overexpressing rat angiotensinogen gene in the kidney. Kidney Int 69:1016-1023

88. Sauer B (1993) Manipulation of transgenes by site-specific recombination: use of Cre recombinase. Methods Enzymol 225:890-900

89. Sauvain M, Dorr A, Stevenson B, Quazzoloa A, Naef F, Wiznerowicz M, Schütz F, Jongeneel V, Duboule D, Spitz F, Trono D (2008) Genotypic features of lentiviral transgenic mice. J Virol 82:7111-7119

90. Scangos G, Bieberich C (1987) Gene transfer into mice. Adv Genet 24:285-322

91. Schneider MP, Ge Y, Pollock DM, Pollock JS, Kohan DE (2008) Collecting duct-derived endothelin regulates arterial pressure and $\mathrm{Na}$ excretion via nitric oxide. Hypertension 51:1605-1610

92. Schönig K, Schwenk F, Rajewsky K, Bujard H (2002) Stringent doxycycline dependent control of CRE recombinase in vivo. Nucleic Acids Res 30:e134

93. Schwartzberg P, Goff S, Robertson E (1989) Germ-line transmission of a c-abl mutation produced by targeted gene disruption in ES cells. Science 246:799-803

94. Scott B, Lois C (2005) Generation of tissue-specific transgenic birds with lentiviral vectors. Proc Natl Acad Sci U S A 102:16443-16447

95. Sequeira Lopez M, Pentz E, Nomasa T, Smithies O, Gomez R (2004) Renin cells are precursors for multiple cell types that switch to the renin phenotype when homeostasis is threatened. Dev Cell 6:719-728

96. Shao X, Somlo S, Igarashi P (2002) Epithelial-specific Cre/lox recombination in the developing kidney and genitourinary tract. J Am Soc Nephrol 13:1837-1846

97. Simpson E, Linder C, Sargent E, Davisson M, Mobraaten L, Sharp J (1997) Genetic variation among 129 substrains and its importance for targeted mutagenesis in mice. Nat Genet 16:1927

98. Smith AJH, De Sousa MA, Kwabi-Addo B, Heppell-Parton A, Impey H, Rabbitts P (1995) A site-directed chromosomal translocation induced in embryonic stem cells by Cre-loxP recombination. Nat Genet 9:376-385 
99. Soriano P (1999) Genaralized lacZ expression with the ROSA26Cre reporter strain. Nat Genet 21:70-71

100. Stricklett PK, Taylor D, Nelson RD, Kohan DE (2003) Thick ascending limb-specific expression of Cre recombinase. Am J Physiol Renal Physiol 285:F33-F39

101. Szule J, Wiznerowicz M, Sauvain M, Trono D, Aebischer P (2006) A versatile tool for conditional gene expression and knockdown. Nature Methods 3:109-116

102. Taketo M, Schroeder A, Mobraaten L, Gunning K, Hanten G, Fox R, Roderick T, Stewart C, Lilly F, Hansen C, Overbeek P (1991) FVB/N: An inbred mouse strain preferable for transgenic analyses. Proc Natl Acad Sci U S A 88:2065-2069

103. Thivierge C, Kurbegovic A, Couillard M, Guillaume R, Cote O, Trudel M (2006) Overexpression of PKD1 causes polycystic kidney disease. Mol Cell Biol 26:1538-1548

104. Thomas K, Folger K, Capecchi MR (1986) High frequency targeting of genes to specific sites in the mammalian genome. Cell 44:419-428

105. Thompson S, Clarke A, Pow A, Hooper M, Melton D (1989) Germ line transmission and expression of a corrected HPRT gene produced by gene targeting in embryonic stem cells. Cell $56: 313-321$

106. Threadgill D, Yee D, Matin A, Nadeau J, Magnuson T (1997) Genealogy of the 129 inbred strains: $129 / \mathrm{SvJ}$ is a contaminated inbred strain. Mamm Genome 8:390-393

107. Tiwari S, Sharma N, Gill PS, Igarashi P, Kahn CR, Wade JB, Ecelbarger CM (2008) Impaired sodium excretion and increased blood pressure in mice with targeted deletion of renal epithelial insulin receptor. Proc Natl Acad Sci U S A 105:6469-6474

108. Traykova-Brauch M, Schonig K, Greiner O, Miloud T, Jauch A, Bode M, Felsher D, Glick A, Kwiatkowski D, Bujard H, Horst J, von Knebel Doeberitz M, Niggli F, Kriz W, Grone H, Koesters R (2008) An efficient and versatile system for acute and chronic modulation of renal tubular function in transgenic mice. Nat Med 14:985-921

109. Vincent S, Robertson E (2004) Targeted insertion of an IRES Cre into the Hnf4a locus: Cre-mediated recombination in the liver, kidney, and gut epithelium. Genesis 39:206-211
110. Wagner E, Stewart T, Mintz B (1981) The human ß-globin gene and a functional thymidine kinase gene in developing mice. Proc Natl Acad Sci U S A 78:5016-5020

111. Wang Q, Clement S, Gabbiani G, Horisberger J-D, Burnier M, Rossier BC, Hummler E (2004) Chronic hyperaldosteronism in a transgenic mouse model fails to induce cardiac remodeling and fibrosis under a normal salt-diet. Am J Physiol Renal Physiol 286:F1178-F1184

112. Yang JY, Tam WY, Tam S, Guo H, Wu X, Li G, Chau JF, Klein JD, Chung SK, Sands JM, Chung SS (2006) Genetic restoration of aldose reductase to the collecting tubules restores maturation of the urine concentrating mechanism. Am J Physiol Renal Physiol 291:F186-F195

113. Yu J, Carroll TJ, McMahon AP (2002) Sonic hedgehog regulates proliferation and differentiation of mesenchymal cells in the mouse metanephric kidney. Development 129:5301-5312

114. Zachgo J, Gossler A (1993) Gene and enhancer trap screens in ES cell chimeras. In: Joyner A (ed) Gene targeting a practical approach. IRL, Oxford, pp 181-227

115. Zbikowska HM, Soukhareva N, Behnam R, Chang R, Drews R, Lubon H, Hammond D, Soukharev S (2002) The use of the uromodulin promoter to target production of recombinant proteins into urine of transgenic animals. Transgenic Res 11:425-435

116. Zbikowska HM, Soukhareva N, Behnam R, Lubon H, Hammond D, Soukharev S (2002) Uromodulin promoter directs high-level expression of biologically active human alpha1-antitrypsin into mouse urine. Biochem J 365:7-11

117. Zhang H, Zhang A, Kohan DE, Nelson RD, Gonzalez FJ, Yang $\mathrm{T}$ (2005) Collecting duct-specific deletion of peroxisome proliferator-activated receptor gamma blocks thiazolidinedioneinduced fluid retention. Proc Natl Acad Sci U S A 102:9406-9411

118. Zhao H, Kegg H, Grady S, Truong HT, Robinson ML, Baum M, Bates CM (2004) Role of fibroblast growth factor receptors 1 and 2 in the ureteric bud. Dev Biol 276:403-415

119. Zhu X, Cheng J, Huang L, Gao J, Zhang ZT, Pak J, Wu XR (2003) Renal tubule-specific expression and urinary secretion of human growth hormone: a kidney-based transgenic bioreactor growth. Transgenic Res 12:155-162 